\title{
Viruses and asthma exacerbations
}

\author{
N G Papadopoulos, S L Johnston
}

For many years general opinion has been that upper respiratory viruses were the cause of the common cold but were able to produce serious complications only in infants, the elderly, and immunocompromised subjects. Although a connection between upper respiratory infections and asthma had long been recognised, the potential importance of the association was probably underestimated until relatively recently when it was shown that, in the community, $85 \%$ of asthma attacks in children ${ }^{1}$ and $44 \%$ in adults ${ }^{2}$ are precipitated by upper respiratory infections.

The last two years have also provided evidence that "common cold" viruses can also induce severe asthma. In a time trend analysis comparing the seasonal patterns of respiratory infections and hospital admissions for asthma in children and adults, ${ }^{3}$ strong correlations were observed in both groups. The major factor determining paediatric admissions was school attendance, and the peaks of both respiratory infections and asthma admissions occurred at the beginning of school terms. In these studies rhinovirus infections are numerically the most important, accounting for $60 \%$ of viruses detected. In another study Teichtahl et al documented the incidence of respiratory tract infections in adults requiring admission to hospital for acute asthma. ${ }^{4}$ Thirty seven percent of their patients recruited during one year had evidence of infection, and viruses were identified by culture and/or serology in $80 \%$ of these cases.

A similar time trend analysis was used to investigate the possible contribution of virus infections to asthma mortality. ${ }^{5}$ Winter peaks in asthma mortality were observed in children under five and in adults over 45 years, suggesting that virus infections also precipitate asthma deaths in these age groups. Interestingly, in asthmatic subjects aged 5-44 years there was a strong summer peak (July/August). The reasons for this are presently unclear but may include alterations in the use of asthma medication or in access to medical care during the holiday season. A further possibility is sensitisation to mould spores as levels of these peak at that time of year. ${ }^{6}$ Further studies directly examining the role of upper respiratory infections and other factors such as allergen exposure in precipitating severe asthma attacks are required. To be successful, however, these studies should use the best available methods of detection.

\section{Virus detection methods}

Rhinoviruses and coronaviruses cause about $75 \%$ of upper respiratory infections but are detected very poorly by standard methods of detection. Virus identification rates have therefore been considerably underestimated when combinations of serology, immunofluorescence, or culture have been the only methods used. ${ }^{7}$ The task of developing, improving, and evaluating polymerase chain reaction (PCR) based techniques for respiratory viruses is currently being undertaken by several groups. DNA based methods can identify up to 10 times more positive samples for some viruses. ${ }^{8}$ PCR assays are now published for all the common respiratory viruses and their use results in decreased numbers of unidentified samples and detection of increased numbers of concurrent infections. ${ }^{9}$ Epidemics commonly produced by influenza viruses can also be successfully surveyed centrally on clinical specimens sent through the post. ${ }^{10}$ PCR is particularly helpful in the case of rhinoviruses (which are notorious for their culture fastidiousness while the great number of rhinovirus serotypes also precludes serology), and for coronaviruses where no standard methods are successful. These methods are, however, only available for research purposes at present as considerable further standardisation and validation is required.

Mechanisms of virus induced asthma exacerbations A fuller understanding of the mechanisms of virus induced asthma exacerbations will hopefully lead to the identification of new potential targets for the development of novel therapeutic interventions. An important question to answer initially is: do virus infections exacerbate asthma directly by local mechanisms consequent upon lower airway infection, or do they infect only the upper respiratory tract and affect the lower airway indirectly? Opinion to date has suggested that rhinoviruses are not able to infect the lower airway, though there have been few data available to argue either way. In a recent study well designed to control for upper airway contamination, Gern et al used PCR to assess lower airway rhinovirus load during experimental infections. ${ }^{11}$ Bronchoalveolar lavage (BAL) cells were positive during the infection in over $80 \%$ of their samples, while only $37 \%$ of BAL fluid specimens were positive, suggesting that rhinoviruses are indeed able to infect the lower airway and that rhinovirus RNA was largely cell associated.

A further subject attracting considerable recent attention is the interaction between virus infections and allergy. It is known that simultaneous virus infection and positive specific IgE for inhalant allergens have a much higher odds ratio for the development of wheezing than any of the factors alone. ${ }^{12}$ Schwarze et al used a murine model to show that respiratory syncytial virus infection not only produces airway hyperresponsiveness in the acute phase, but also subsequently enhances allergen sensitisation-notably, pulmonary eosinophilic infiltration was observed in both situations. ${ }^{13}$ An enhanced reaction to allergen inhalation in allergic patients experimentally infected with rhinovirus has also been demonstrated. ${ }^{14}$ These data suggest that concurrent virus infection can increase the airway response to allergen (perhaps by increasing penetration of allergen through the damaged epithelium), but little is known about the reverse possible interaction. Effective virus clearance requires effective Th1 type responses. Asthma is clearly associated with Th2 type responses and might therefore be expected to be associated with less efficient virus clearance or more severe infections. Several studies have confirmed that asthmatic subjects have more severe symptoms during virus infections, ${ }^{7}$ but it is not known if the virus load or the residence time is greater.

Induction of non-specific bronchial hyperresponsiveness is a feature of asthma and a well documented result of viral infection in allergic subjects, ${ }^{15}{ }^{16}$ though this induction has not been observed in all studies. ${ }^{17}$ This discrepancy in observations is probably related to differences in virus dose and/or in the inoculation method used. ${ }^{18}$

Inflammatory cell infiltration is another important feature of asthma which has been observed with human experimental rhinovirus infection studies examining induced sputum (increased eosinophil products) ${ }^{19}$ or bronchial biopsy specimens (lymphocyte and eosinophil 
infiltrate $)^{20}$ of asthmatic patients. Inflammatory cells such as eosinophils, neutrophils, and lymphocytes, as well as the expression of intercellular adhesion molecule 1 (ICAM-1), were also found to be significantly increased in atopic subjects compared with non-atopic subjects experiencing natural colds. ${ }^{21}$ Neutrophils are also implicated in the response to virus infection; their products have been observed in nasal secretions during wild type colds ${ }^{22}$ and increased staining for IL- 8 was observed in neutrophils in sputum during experimental rhinovirus infections. ${ }^{19}$

The cytokines regulating the inflammatory cell infiltrate in virus induced asthma and the mechanisms controlling their induction or release are clearly of great current interest. Interleukin 8 (IL-8) has been implicated in the pathogenesis of respiratory virus infection and asthma. Rhinoviruses were found to induce IL-8 release from monocytes for up to a week after inoculation onto peripheral blood mononuclear cells. ${ }^{23}$ While some respiratory viruses are able to replicate inside monocytes and macrophages, this does not seem to be the case with rhinoviruses, ${ }^{24}$ even though low grade replication was shown in a human monocyte cell line. ${ }^{23}$ The function of IL- 8 as a chemotactic factor for neutrophils and primed eosinophils indicates that it may play an important part in triggering the inflammation that leads to exacerbations of asthma. Indeed, IL-8 has been detected in increased amounts in both nasal ${ }^{22}$ and bronchial ${ }^{19}$ samples taken during virus infections, and levels correlated with induction of bronchial hyperreactivity. ${ }^{18}$

Likewise, the proinflammatory cytokine IL-6 was found to be induced by rhinoviruses, ${ }^{25}$ and IL-6 was also increased in the sputum of rhinovirus infected asthmatic subjects. ${ }^{19}$ Another recent candidate which may be important in the pathogenesis of virus induced asthma is IL-11. Several viruses including respiratory syncytial and parainfluenza viruses and rhinovirus strongly stimulated its production by stromal cells. Furthermore, it was detected in nasal aspirates from children with upper respiratory infection and its levels were correlated with clinically detectable wheezing. ${ }^{26}$ With regard to the intracellular mechanisms of cytokine induction, factors binding to the $\mathrm{NF \kappa B}$ transcription factor binding site on the IL- 6 promoter were shown to be involved, ${ }^{25}$ but it is not yet known whether blocking the activity of this transcription factor is sufficient to inhibit virus induction of proinflammatory cytokines.

Such interesting observations on the epidemiology, diagnosis, and pathophysiology of virus induced asthma are beginning to suggest new candidate molecules that might represent targets for novel therapeutic interventions. It is hoped that further advances in our understanding of the cellular and molecular mechanisms involved will lead to more clear identification of such targets, and the development of blocking strategies suitable for testing in the clinic. In the meantime, we will have to continue to use increased doses of inhaled or oral steroids until more effective antiviral therapies are available. ${ }^{27}$
N G PAPADOPOULOS S L JOHNSTON

Southampton General Hospital,

Southampton SO16 6YD,

UK

1 Johnston SL, Pattemore PK, Sanderson G, et al. Community study of role of viral infections in exacerbations of asthma in 9-11 year old children. $B M \mathcal{F}$ $1995 \cdot 310: 1225-8$.

2 Nicholson KG, Kent J, Ireland DC. Respiratory viruses and exacerbations of asthma in adults. BMF 1993;307:982-6.

3 Johnston SL, Pattemore PK, Sanderson G, et al. The relationship between upper respiratory infections and hospital admissions for asthma: a time trend analysis. Am $\mathcal{F}$ Respir Crit Care Med 1996;154:654-60.

4 Teichtahl H, Buckmaster N, Pertnikovs E. The incidence of respiratory tract infections in adults requiring hospitalization for asthma. Chest 1997;112: 591-6.

5 Campbell MJ, Holgate ST, Johnston SL. Trends in asthma mortality. BMF 1998;315:1012.

6 Durham S. ABC of allergies. Summer hay fever. BMF 1998;316:843-5.

7 Pattemore PK, Johnston SL, Bardin PG. Viruses as precipitants of asthma symptoms, Part I. Epidemiology. Clin Exp Allergy 1992;22:325-36.

8 Freymuth F, Vabret A, Galateau-Salle F, et al. Detection of respiratory syncytial virus, parainfluenza virus 3 , adenovirus and rhinovirus sequences in cytial virus, parainfluenza virus 3 , adenovirus and rhinovirus sequences in
respiratory tract of infants by polymerase chain reaction and hybridization. respiratory tract of infants by po
Clin Diagn Virol 1997;8:31-40.

9 Gilbert LL, Dakhama A, Bone BM, et al. Diagnosis of viral respiratory tract infections in children by using a reverse transcription-PCR panel. $\mathcal{F}$ Clin Microbiol 1996;34:140-3.

10 Ellis JS, Fleming DM, Zambon MC. Multiplex reverse transcription-PCR for surveillance of influenza A and B viruses in England and Wales in 1995 and 1996. $\mathcal{F}$ Clin Microbiol 1997;35:2076-82.

11 Gern JE, Galagan DM, Jarjour NN, et al. Detection of rhinovirus RNA in lower airway cells during experimentally induced infection. Am 7 Respir Crit Care Med 1997;155:1159-61.

12 Duff AL, Pomeranz ES, Gelber LE, et al. Risk factors for acute wheezing in infants and children: viruses, passive smoke, and $\operatorname{IgE}$ antibodies to inhalant allergens. Pediatrics 1993;92:535-40.

13 Schwarze J, Hamelmann E, Bradley KL, et al. Respiratory syncytial virus Schwarze J, Hamelmann E, Bradley $\mathrm{KL}$, et al. Respiratory syncytial virus
results in airway hyperresponsiveness and enhanced airway sensitization to results in airway hyperresponsiveness and
allergen. $\mathcal{F}$ Clin Invest 1997;100:226-33.

14 Calhoun WJ, Dick EC, Schwartz LB, et al. A common cold virus, rhinovirus 16 , potentiates airway inflammation and segmental allergen bronchoprovocation in allergic subjects. $\mathcal{F}$ Clin Invest 1994;94:2200-8.

15 Folkerts G, Nijkamp FP. Virus induced airway hyperresponsiveness. Role of inflammatory cells and mediators. Am F Respir Crit Care Med 1995;151: 1666-74.

16 Gern JE, Calhoun W, Swenson C, et al. Rhinovirus infection preferentially increases lower airway responsiveness in allergic subjects. Am f Respir Crit Care Med 1997;155:1872-6.

17 Skoner DP, Doyle WJ, Seroky J, et al. Lower airway responses to influenza A virus in healthy allergic and nonallergic subjects. Am f Respir Crit Care Med 1996;154:661-4.

18 Johnston SL. Bronchial hyperresponsiveness and cytokines in virus-induced asthma exacerbations. Clin Exp Allergy 1997;27:7-9.

19 Grunberg K, Smits HH, Timmers MC, et al. Experimental rhinovirus 16 infection. Effects on cell differentials and soluble markers in sputum of infection. Effects on cell differentials and soluble markers in

20 Fraenkel DJ, Bardin PG, Sanderson G, et al. Lower airways inflammation during rhinovirus colds in normal and in asthmatic subjects. Am $\mathcal{F}$ Respir Crit Care Med 1995;151:879-86.

21 Trigg CJ, Nickolson KG, Wang JH, et al. Bronchial inflammation and the common cold: a comparison of atopic and non-atopic individuals. Clin Exp Allergy 1996;26:665-76.

22 Teran LM, Johnston SL, Schröder J, et al. Role of nasal interleukin-8 in neutrophil recruitment and activation in children with virus-induced asthma. Am f Respir Crit Care Med 1997;155:1362-6.

23 Johnston SL, Papi A, Monick MM, et al. Rhinoviruses induce interleukin-8 mRNA and protein production in human monocytes. $\mathcal{F}$ Infect Dis 1997;175:323-9.

24 Gern JE, Dick EC, Lee WM, et al. Rhinovirus enter but does not replicate inside monocytes and airway macrophages. F Immunol 1996;156:621-7.

25 Zhu Z, Tang W, Ray A, et al. Rhinovirus stimulation of interleukin-6 in vivo and in-vitro. $\mathcal{F}$ Clin Invest 1996;97:421-30.

26 Einarsson O, Geba GP, Zhu Z, et al. Interleukin-11:stimulation in vivo and in vitro by respiratory viruses and induction of airways hyperresponsiveness. F Clin Invest 1996;97:915-24.

27 Johnston SL. Problems and prospects of developing effective therapy for common cold viruses. Trends Microbiol 1997;5:58-63. 